\title{
Response in Relation to Baseline Anxiety Levels in Major Depressive Disorder Treated with Bupropion Sustained Release or Sertraline
}

\author{
A. John Rush, M.D., Madhukar H. Trivedi, M.D., Thomas J. Carmody, Ph.D., \\ Rafe M.J. Donahue, Ph.D., Trisha L. Houser, B.A., Carolyn Bolden-Watson, Ph.D., \\ Sharyn R. Batey, Pharm.D., John A. Ascher, M.D., and Alan Metz, M.D.
}

Our objective was to determine if pretreatment anxiety levels were associated with preferential response to bupropion sustained release $(n=122)$ or sertraline $(n=$ 126) during a 16-week randomized acute phase treatment study. Both agents had comparable antidepressant activity, and comparable anxiolytic effects using the intent-to-treat sample. Baseline anxiety levels were not related to antidepressant efficacy, and they did not differentiate responders to each agent. Time to clinically significant anxiolysis did not differentiate between treatment groups or between responders to each agent. These results contradict the commonly held, but unsubstantiated, belief that in clinically depressed anxious patients, serotonergic antidepressants are especially anxiolytic and that such patients preferentially benefit from the antidepressant or anxiolytic effects of selective serotonin reuptake inhibitors. Thus, the clinical decision to select between these two agents when treating depressed outpatients cannot rest on either levels of pretreatment anxiety or on anticipation of more rapid or more complete anxiolysis.

[Neuropsychopharmacology 25:131-138, 2001] (C) 2001 American College of Neuropsychopharmacology. Published by Elsevier Science Inc.
KEY WORDS: Major depressive disorder; Bupropion SR; Sertraline; Anxiolysis; Pretreatment anxiety; Retrospective analysis

From the Department of Psychiatry (AJR, MHT) and Academic Computing Services (TJC), University of Texas Southwestern Medical Center, Dallas, TX; and Division of US Medical Affairs (RMJD, TLH, CBW, AM) and Clinical Development (SRB, JAA), Glaxo Wellcome, Inc., Research Triangle Park, NC.

Address correspondence to: A. John Rush, M.D., Department of Psychiatry, University of Texas Southwestern Medical Center, 5323 Harry Hines Blvd., Dallas, TX 75390-9086.

Received 14 June 2000; revised 29 November 2000; accepted 4 December 2000.

Findings presented, in part, at the annual meeting of the American College of Neuropsychopharmacology, Acapulco, Mexico, December 11-16, 1999, the annual meeting of the American Psychiatric Association, Chicago, IL, May 13-18, 2000, and the annual meeting of the New Clinical Drug Evaluation Unit, Boca Raton, FL, May 30-June 2, 2000.
Bupropion hydrochloride sustained release (SR) and sertraline have demonstrated antidepressant efficacy in randomized, double-blind, placebo-controlled studies in outpatients with major depressive disorder (Reimherr et al. 1990, 1998; Fabre et al. 1995; Croft et al. 1999; Coleman et al. 1999). Bupropion has demonstrated comparable antidepressant efficacy to sertraline (Kavoussi et al. 1997; Croft et al. 1999; Coleman et al. 1999), fluoxetine (Feighner et al. 1991), and paroxetine (Weihs et al. 2000) in outpatients with major depressive disorder. Compared with other antidepressants, bupropion SR is among the least sedating ones (American Psychiatric Association 1993). Sertraline has established efficacy in anxiety disorders (Pfizer, Inc. 1996), particularly in panic disorder (Sheehan 1999) and obsessive-compulsive disorder (Goodman 1999). In addition, sertraline has recently received FDA-approval for the treatment of posttraumatic stress disorder (Henney 2000). 
Depression is often associated with substantial anxiety symptoms or even concomitant formal anxiety disorders. Fawcett (1997), Clayton and colleagues (1991), and others (e.g., Joffe et al. 1993) have found that significant anxiety symptoms: 1 ) are commonly found in major depressive disorder; 2) are associated with greater overall depressive symptom severity, and greater functional impairment; 3) are associated with greater suicide risk; and 4) may be associated with poorer treatment responses. No single antidepressant is effective for all patients (Depression Guideline Panel 1993).

In order to choose among antidepressants, some clinicians rely on pretreatment symptom features to inform their selection of the initial medication. Some practitioners believe that matching medication side effects and presenting symptoms is a useful approach. For example, some suggest that more sedating agents are preferable in more anxious patients, whereas more activating agents might be preferred in those patients with greater psychomotor retardation (Blackwell 1987). Alternatively, one could assume that antidepressant agents with indications for anxiety disorders (e.g., sertraline and paroxetine) might either be more effective or produce more rapid anxiolysis in depressed patients with high levels of baseline anxiety. While these beliefs are common, available evidence is strikingly unsupportive (Tyrer et al. 1980; Tollefson et al. 1994; Stokes and Holtz 1997; Simon et al. 1998).

Bupropion SR, a norepinephrine and dopamine reuptake inhibitor (NDRI) is thought to act with no effect on serotonergic function, or affinity for postsynaptic receptors. Sertraline is a selective serotonin reuptake inhibitor (SSRI) whose mechanism of action is presumably linked to its inhibition of central nervous system (CNS) neuronal uptake of serotonin (5-HT). Some believe that 5-HT active agents (as opposed to norepinephrine active) will produce more rapid anxiolysis or will be more effective in clinically depressed patients with substantial levels of baseline anxiety.

Previously, a retrospective analysis was conducted using pooled data from two identical 8-week acute phase depression studies comparing bupropion SR, sertraline and placebo, found that pretreatment anxiety was unrelated to antidepressant response to either bupropion SR or sertraline (Rush et al. 2001). Furthermore, a retrospective analysis of the same 8-week acute phase dataset revealed that bupropion SR and sertraline were equivalently effective in reducing anxiety over the course of the 8-week study (Rush et al. 2000).

The safety and antidepressant efficacy results of the present 16-week study have been published elsewhere (Kavoussi et al. 1997), as have the findings regarding the effects of bupropion SR and sertraline on sexual functioning (Segraves et al. 2000). The present analyses were conducted on this 16-week acute phase trial comparing bupropion SR and sertraline (Kavoussi et al. 1997; Seg- raves et al. 2000). We wished to know whether the previous findings using an 8-week dataset (Rush et al. 2001; Rush et al. 2000) would pertain to a longer (16 week) acute phase trial (present data set) to answer the following questions: 1) are baseline anxiety levels associated with differential response to bupropion SR?; 2) are baseline anxiety levels associated with differential response to sertraline?; 3) do baseline anxiety levels predict differential response between bupropion SR and sertraline (i.e., do responders to bupropion SR have different levels of baseline anxiety than responders to sertraline)?; and 4) do antidepressant responders to either sertraline or bupropion SR differ in the time to the onset of clinically significant anxiety reduction?

\section{METHODS}

\section{Study Population}

This randomized, double-blind, parallel-group, multicenter study was conducted in outpatients with moderate to severe, recurrent major depressive disorder according to Diagnostic and Statistical Manual of Mental Disorders-Fourth Edition (DSM-IV) criteria (American Psychiatric Association 1994). The Institutional Review Board for each study site approved the protocol and written informed consent was obtained from each patient after the procedures had been fully explained. The study was carried out in accordance with the Declaration of Helsinki.

Screening and baseline medical (medical and psychiatric history, physical exam, and laboratory assessments (CBC and chemistry panels) and psychiatric assessments were performed, including a 31-item modification of the Hamilton Rating Scale for Depression (HAM-D) (Hamilton 1960, 1967), Clinical Global Impressions Scales for Severity of Illness (CGI-S) and Improvement of Illness (CGI-I) (beginning at Week 1) (Guy 1976), and the 14-item Hamilton Rating Scale for Anxiety (HAM-A) (Hamilton 1959). Patients enrolled in the study were required to: 1 ) be experiencing single or recurrent major depressive disorder as diagnosed by DSM-IV; 2) score at least 18 on the 21-item HAM-D; and 3) be suitable for treatment with bupropion SR or sertraline. Patients were randomized to receive either bupropion SR (100-300 mg/day) or sertraline (50-200 $\mathrm{mg}$ /day) for up to 16 weeks. Assessments of depression and anxiety were made at each clinic visit during Weeks 1, 2, 3, 4, 6, 8, 12, and 16. Efficacy was evaluated by the 17-, 21-, and 31-item HAM-D, and the CGI-I, CGI-S, and HAM-A.

\section{Analytic Procedures}

The HAM- $\mathrm{D}_{21}$ total score was the primary efficacy variable in this retrospective analysis. To answer questions 
1 and 2 (from above), analyses of covariance (ANCOVA) were used to explain percentage change in HAM-D ${ }_{21}$ total score from baseline to exit as a function of investigative site with baseline HAM-A and HAM- $D_{21}$ scores as covariates for patients treated with bupropion SR or sertraline. In addition, logistic regression was used to model the probability of antidepressant response (defined as $\geqslant 50 \%$ reduction in baseline HAM- $\mathrm{D}_{21}$ score) or remission (defined as final HAM- $\mathrm{D}_{21}$ score of $\leqslant 8$ ) using terms for investigative site, baseline HAM-A score, and baseline HAM- $\mathrm{D}_{21}$ score. To confirm the HAM- $\mathrm{D}_{21}$ findings, 17- and 31-item HAM-D percentage change scores, along with raw change scores for the 17-, 21-, and 31-item HAM-D, were also analyzed as described above.

To determine whether responders to bupropion SR differed in baseline anxiety levels from responders to sertraline (question 3 above), ANCOVA was used to explain percentage change in $\mathrm{HAM}-\mathrm{D}_{21}$ total score at study exit as a function of investigative site and treatment group with baseline HAM-A and HAM- $\mathrm{D}_{21}$ scores as covariates. Interactions between treatment group and the covariates were used to test for unequal slopes. Logistic regression was used to model the probability of response and remission with terms for investigative site, treatment group, baseline HAM-A score, baseline HAM- $D_{21}$ score, and interactions between treatment group and baseline scores.

Plots showing the relationship between baseline HAM-A score and percentage change (baseline to exit) in HAM- $D_{21}$ score were created for each treatment group. Also, patients were partitioned into quartiles using the baseline HAM-A total score and the proportions of responders and remitters by quartile were displayed for each treatment group. We also provided counts of patients with "clinically significant" changes in anxiety from baseline (defined as 2- or 3-point increases or decreases in baseline HAM-A total score) for each group, to ensure the group data did not fail to detect clinically important individual patient differences between the two treatments.

To answer question 4 above, survival analyses were used to test for differences between the two treatments in time to "clinically significant" anxiolysis (defined as $a \geqslant 50 \%$ reduction in baseline HAM-A total score) for each patient. ANCOVA was used to model percentage change in HAM- $\mathrm{D}_{21}$ score at discontinuation, with baseline HAM-A and HAM- $\mathrm{D}_{21}$ scores as covariates for patients in each treatment group.

\section{RESULTS}

Data from 248 patients were available for efficacy evaluations. Table 1 provides the clinical and demographic features of the sample. Baseline clinical and demographic characteristics were similar between the two treatment groups. Table 2 provides symptom information at baseline and endpoint for each treatment cell. Figure 1 presents the mean HAM- $\mathrm{D}_{21}$ last observation carried forward (LOCF) scores for both treatment groups. Baseline mean HAM- $\mathrm{D}_{21}$ scores were 24.8 for both the bupropion SR (SD \pm 4.6$)$ and sertraline (SD \pm 4.6) treatment groups. Mean HAM- $\mathrm{D}_{21}$ LOCF scores at end of study were $9.3(\mathrm{SD} \pm 8.4)$ and $8.5(\mathrm{SD} \pm 9.0)$ for the bupropion SR and sertraline treatment groups, respectively. ANCOVA, using change from baseline HAM-D ${ }_{21}$ scores, showed no statistically significant differences between bupropion SR and sertraline.

Figure 2 shows the relationship between baseline

Table 1. Baseline Clinical and Demographic Characteristics

\begin{tabular}{|c|c|c|c|c|c|c|}
\hline \multirow[b]{2}{*}{ Characteristic } & \multicolumn{3}{|c|}{ Bupropion SR $(n=122)$} & \multicolumn{3}{|c|}{ Sertraline $(n=126)$} \\
\hline & $n$ & Range & Mean or $\%$ & $n$ & Range & Mean or $\%$ \\
\hline Age (yr) & & $(19-76)$ & 39 & & $(18-74)$ & 40 \\
\hline Female $^{a}$ & 59 & - & $48 \%$ & 60 & - & $48 \%$ \\
\hline \multicolumn{7}{|l|}{ Ethnic Origin } \\
\hline White & 113 & - & $93 \%$ & 119 & - & $94 \%$ \\
\hline Black & 7 & - & $6 \%$ & 4 & - & $3 \%$ \\
\hline Other & 2 & - & $2 \%$ & 3 & - & $2 \%$ \\
\hline \multicolumn{7}{|l|}{ Length of current episode } \\
\hline $2-6$ months & 37 & - & $30 \%$ & 44 & - & $35 \%$ \\
\hline $7-12$ months & 44 & - & $36 \%$ & 48 & - & $38 \%$ \\
\hline 12-24 months & 41 & - & $34 \%$ & 34 & - & $27 \%$ \\
\hline Premature discontinuation & 35 & - & $29 \%$ & 43 & - & $34 \%$ \\
\hline Modal dose (mg/day) ${ }^{b}$ & - & - & $259 \pm 70.4^{c}$ & - & - & $123 \pm 52.9^{c}$ \\
\hline
\end{tabular}

${ }^{a}$ Enrollment was stratified to ensure an equal proportion of males and females entered the study.

bOver all visits.

${ }^{c}$ Mean \pm SD. 
Table 2. Baseline and End of Treatment (Last Visit) Findings

\begin{tabular}{|c|c|c|}
\hline \multirow[b]{2}{*}{ Variable } & \multirow{2}{*}{$\begin{array}{l}\text { Bupropion SR } \\
(n=122) \\
\text { Mean } \pm \text { SD }\end{array}$} & \multirow{2}{*}{$\begin{array}{c}\begin{array}{c}\text { Sertraline } \\
(n=126)\end{array} \\
\text { Mean } \pm \text { SD }\end{array}$} \\
\hline & & \\
\hline \multicolumn{3}{|l|}{ Baseline HAM-A score } \\
\hline Responders & $16.8 \pm 5.2$ & $16.6 \pm 5.2$ \\
\hline Nonresponders & $16.3 \pm 5.1$ & $16.8 \pm 6.2$ \\
\hline \multicolumn{3}{|l|}{ HAM-D ${ }_{21}$ score (total sample) } \\
\hline Baseline & $24.8 \pm 4.6$ & $24.8 \pm 4.6$ \\
\hline Last visit & $9.3 \pm 8.4$ & $8.5 \pm 9.0$ \\
\hline \multicolumn{3}{|l|}{ CGI-S score (total sample) } \\
\hline Baseline & $4.4 \pm 0.7$ & $4.4 \pm 0.7$ \\
\hline Last visit & $2.3 \pm 1.2$ & $2.2 \pm 1.3$ \\
\hline \multicolumn{3}{|l|}{ HAM-A score (total sample) } \\
\hline Baseline & $16.6 \pm 5.2$ & $16.6 \pm 5.4$ \\
\hline Last visit & $6.9 \pm 5.9$ & $6.5 \pm 6.9$ \\
\hline \multicolumn{3}{|l|}{ Last Visit } \\
\hline Response by HAM-D ${ }_{21}^{a}$ & $66 \%$ & $74 \%$ \\
\hline Response by CGI-I ${ }^{\mathrm{b}}$ & $67 \%$ & $74 \%$ \\
\hline Remission by HAM- $D_{21}{ }^{c}$ & $55 \%$ & $63 \%$ \\
\hline
\end{tabular}

${ }^{a}$ Defined as a reduction of at least $50 \%$ from baseline HAM- $\mathrm{D}_{21}$ score. ${ }^{\mathrm{b}}$ Defined as CGI-I score of 1 or 2.

'Defined as final HAM- $\mathrm{D}_{21}$ score $\leqslant 8$.

HAM-A score and percentage change in HAM- $D_{21}$ for both treatment groups. The lack of a relationship between baseline anxiety and percentage change in HAM- $\mathrm{D}_{21}$ score is apparent and consistent across both treatment groups ( $p=.52$ and .92 for bupropion SR and sertraline, respectively). Both treatments were associated with a large percentage change in HAM- $\mathrm{D}_{21}$ as evidenced by the concentration of data points in the region showing greater change from baseline.

Figure 3 shows the proportions of patients with response and remission in each treatment group when patients were partitioned into quartiles using the baseline HAM-A total score. Higher baseline HAM-A scores generally were associated with slightly lower remission rates for both treatment groups. In this sample, baseline HAM-A score was related to baseline HAM- $D_{21}$ score (Pearson correlation $=0.62$ ). Furthermore, analyses failed to show any statistically significant relationship between baseline anxiety level for responders or nonresponders (i.e., baseline anxiety levels were not related to whether or not patients responded to either treatment).

Figure 4 presents the mean HAM-A LOCF scores for the two treatment groups. Baseline mean total HAM-A scores were 16.6 for both the bupropion SR $(\mathrm{SD} \pm 5.2)$ and sertraline (SD \pm 5.4$)$ treatment groups. Mean HAM-A LOCF scores at end of study were 6.9 (SD \pm $5.9)$ and $6.5(\mathrm{SD} \pm 6.9)$ for the bupropion $S R$ and sertraline groups, respectively. No statistically significant differences were observed between bupropion SR and sertraline at any time point. Approximately one-half of all patients ( $55 \%$ for bupropion SR; $54 \%$ for sertraline) achieved anxiolysis by week $4(p=.48)$ and approximately one-half of the HAM- $\mathrm{D}_{21}$ responders $(47 \%$ for bupropion SR; $52 \%$ for sertraline) achieved anxiolysis by week $3(p=0.11)$.

At endpoint (LOCF), there was no difference between bupropion SR and sertraline in reduction from baseline in psychic anxiety $(-7.06 \pm 5.14$ for bupropion SR versus $-7.43 \pm 4.80$ for sertraline) $(p=.326)$ or in reduction from baseline in somatic anxiety $(-2.71 \pm 3.03$ for bupropion SR versus $-2.71 \pm 3.03$ for bupropion SR versus $-2.71 \pm 3.44$ for sertraline) $(p=.547)$.

We counted the number of individuals in each treatment cell (bupropion SR and sertraline) that had reductions, no change, and increases in HAM-A baseline score at study exit using two different definitions of

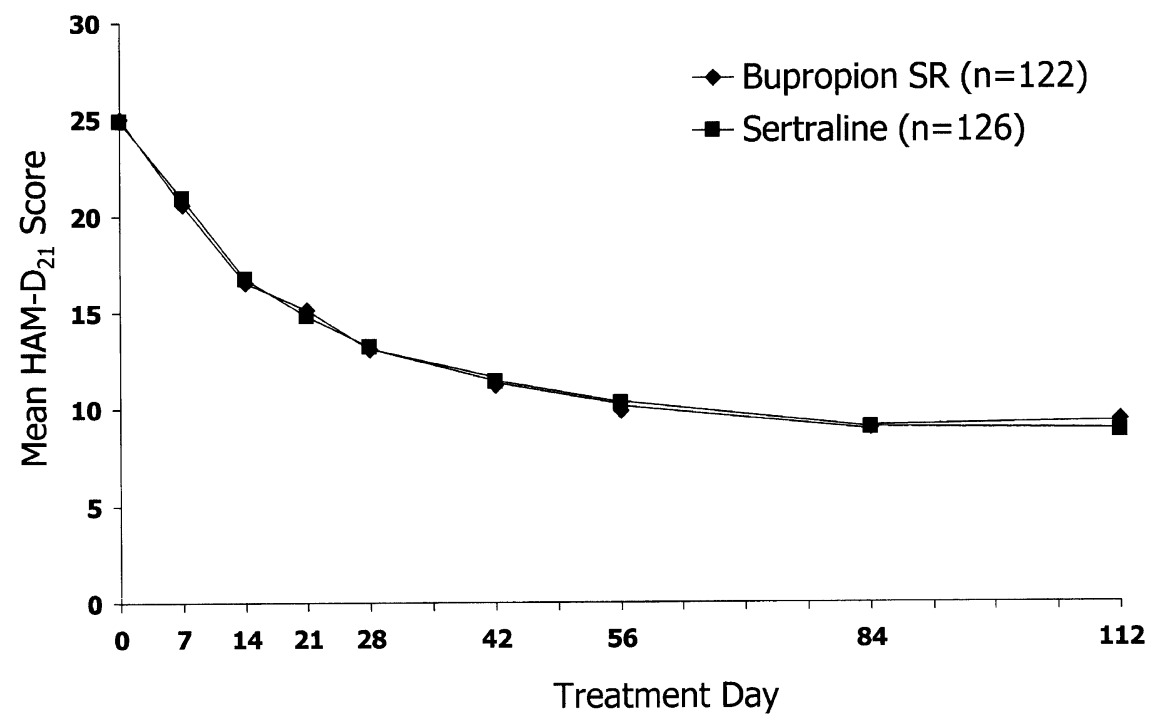

Figure 1. Mean 21-item Hamilton Rating Scale for Depression scores (LOCF) in depressed outpatients receiving bupropion SR or sertraline for 16 weeks. 

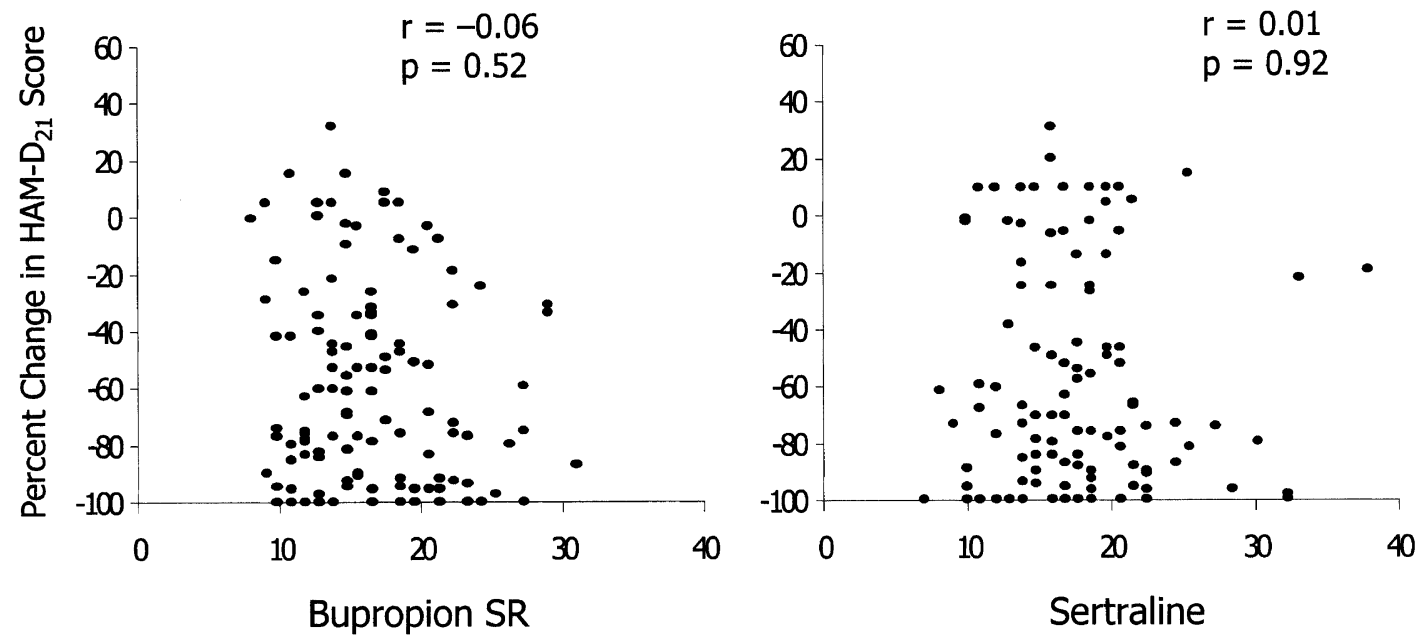

Baseline HAM-A Score

Figure 2. Relationship between Hamilton Rating Scale for Anxiety score and percentage change in 21-item Hamilton Rating Scale for Depression scores at exit.

clinically significant HAM-A changes (2 points and 3 points different from baseline total). There was no meaningful difference between the two treatments of clinically significant change in anxiety, whether defined as an increase or decrease in HAMA total score.

Furthermore, we looked at attrition in relation to each medication for those with increased HAM-A scores defined by both the 2-point and 3-point threshold. None of the subjects with increases in baseline HAM-A scores in either group completed the study (last exit at 42 days). On average, those sertralinetreated patients with increased anxiety exited at 1.7 (2-point definition) or 2.0 weeks (3-point definition). Those bupropion-SR treated patients with increased anxiety exited, on average, at 3.2 (2-point definition) or 4.0 weeks (3-point definition).

\section{DISCUSSION}

Baseline anxiety levels were not related to antidepressant response or remission rates during 16 weeks of treatment with bupropion SR or sertraline. In this study, baseline anxiety levels did not distinguish: 1) pa-
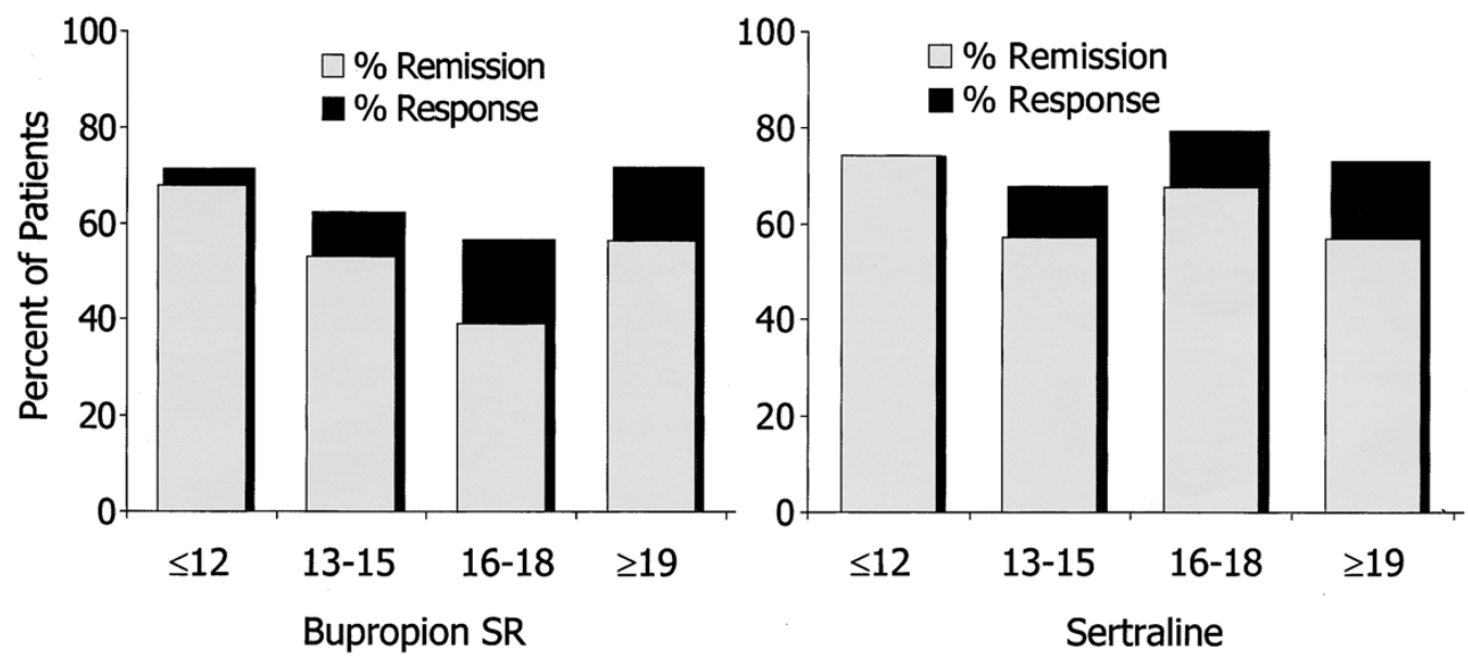

\section{Baseline HAM-A Score}

Figure 3. Percent of patients showing response and remission at exit as a function of baseline Hamilton Rating Scale for Anxiety total scores partitioned into quartiles. 


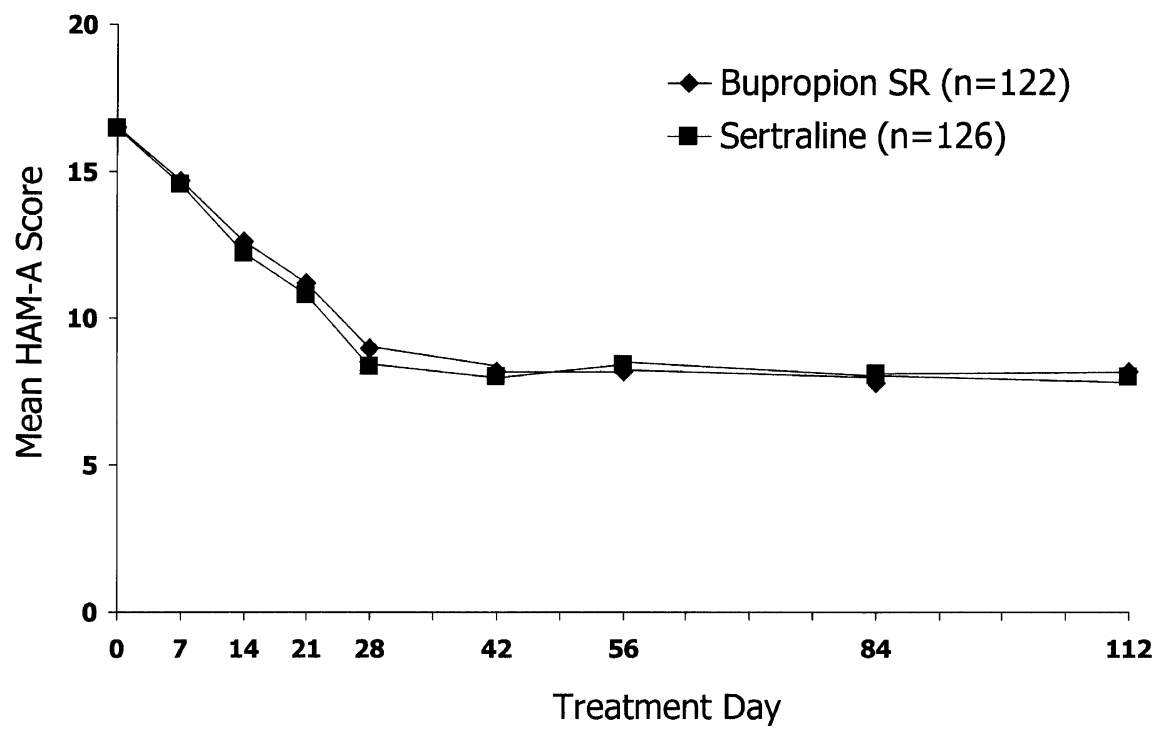

Figure 4. Mean Hamilton Rating Scale for Anxiety scores (LOCF) in depressed outpatients receiving bupropion SR or sertraline for 16 weeks.

tients who responded to bupropion SR from those who responded to sertraline; and 2) those who remitted with one treatment versus the other. Thus, pretreatment anxiety levels in this sample do not provide a basis for selecting between these two antidepressants for the treatment of major depressive disorder. Secondly, pretreatment anxiety levels did not distinguish either between bupropion SR responders and nonresponders, or between sertraline responders and nonresponders. However, higher baseline anxiety levels tended to be associated with very slightly lower remission rates to both treatments.

These findings agree with a previous report using a different sample comparing bupropion SR, sertraline and placebo in an 8-week acute phase trial (Rush et al. 2001). In addition, these results generally agree with other studies, most of which have not found a relationship between baseline anxiety levels and antidepressant response to fluoxetine (Simon et al. 1998; Tollefson et al. 1994), monoamine oxidase inhibitors (MAOIs) (Quitkin et al. 1990), or tricyclic antidepressants (Tyrer et al. 1980). However, Filteau et al. (1995) did find that SSRI responders $(n=28)$ had greater baseline anxiety/agitation levels than responders to norepinephrine reuptake inhibitors.

Furthermore, time to clinically significant anxiolysis was comparable between bupropion SR and sertraline. Again, this finding is in agreement with that of a recently completed report (Rush et al. 2000) using a different sample to compare bupropion SR, sertraline and placebo in an 8-week trial. A count of those patients with clinically significant increases (2- or 3-points above baseline HAM-A total score) revealed no differences between the two medications (bupropion SR: 2-3\%; sertraline: $3-5 \%$ ). Thus, one cannot select between these two agents based on the unsupported belief that use of one as opposed to the other leads to more rapid anxiolysis.

Several limitations pertain to this report: 1) the analyses were retrospective; 2) only outpatients were included; 3) no placebo cell was included; and 4) only patients with a primary diagnosis of major depressive disorder were included. On the other hand, the sample size was substantial. As such, the analyses should have had sufficient power to detect clinically meaningful differences. Thus, the failure to find a relationship between baseline anxiety and antidepressant effects and the failure to find a differential rate of anxiolysis were unlikely to be due to a lack of sufficient power. Furthermore, subjects in this study more likely represented patients who had moderate-to-severe depression since no placebo was present in this trial.

As suggested by the American Psychiatric Association (1993) and Depression Guideline Panel (1993) clinical practice guidelines, the present results are consistent with the notions that: 1) an empirical trial of one followed by another medication is indicated to select the most effective treatment for an individual patient; and 2) issues other than cross-sectional symptom features (e.g., short- and long-term tolerability) may play a more critical role in medication selection. Whether a switch within or out of the initial medication class chosen (e.g., from one SSRI to another, from an SSRI to bupropion SR, or from bupropion SR to an SSRI) deserves study in a randomized controlled trial.

\section{ACKNOWLEDGMENTS}

Supported in part by a contract from Glaxo Wellcome Inc., a contract from the National Institute of Mental Health (Sequenced Treatment Alternatives to Relieve Depression or 
STAR*D) (N01-MH-90003), the Sarah M. and Charles E. Seay Center for Basic and Applied Research in Psychiatry and Mental Health Connections, a Texas State Legislature and Dallas County Hospital District funded partnership between Dallas County Department of Mental Health Mental Retardation, and the Department of Psychiatry, University of Texas Southwestern Medical Center. The authors thank David Savage for secretarial support, and Kenneth Z. Altshuler, M.D., Stanton Sharp Distinguished Chair, Professor and Chairman, Department of Psychiatry, UT Southwestern Medical Center for administrative support. Six of the authors (TLH, RMJD, CBW, SRB, JAA, AM) are employees of Glaxo Wellcome, Inc., Research Triangle Park, NC.

\section{REFERENCES}

American Psychiatric Association (1993): Practice Guidelines for Major Depressive Disorder in Adults. Am J Psychiatry 150(Suppl 4):1-51

American Psychiatric Association (1994): Diagnostic and Statistical Manual of Mental Disorders, 4th ed. Washington, DC, American Psychiatric Association

Blackwell B (1987): Side effects of antidepressant drugs. In Hales RE, Frances AJ (eds), Psychiatry Update: The American Psychiatric Association Annual Review, Vol 6. Washington, DC, American Psychiatric Press, pp 724-745

Clayton PJ, Grove WM, Coryell W, Keller M, Hirschfeld R, Fawcett J (1991): Follow-up and family study of anxious depression. Am J Psychiatry 148:1512-1517

Coleman C, Cunningham L, Foster V, Batey SR, Donahue RMJ, Houser T, Ascher J (1999): Sexual dysfunction associated with the treatment of depression: A placebocontrolled comparison of bupropion sustained release and sertraline treatment. Ann Clin Psychiatry 11:205215

Croft H, Settle E, Houser T, Batey SR, Donahue RMJ, Ascher JA (1999): A placebo-controlled comparison of the antidepressant and sexual functioning effects of bupropion sustained release and sertraline. Clin Ther 21:643-658

Depression Guideline Panel (1993): Clinical Practice Guideline, No. 5. Depression in Primary Care, Vol 2. AHCPR Publication No. 93-0551. Treatment of Major Depression. Rockville, MD, Department of Health and Human Services, Public Health Service, Agency for Health Care Policy and Research

Fabre LF, Abuzzahab FS, Amin M, Claghorn JL, Mendels J, Petrie WM, Dube S, Small JG (1995): Sertraline safety and efficacy in major depression: A double-blind fixeddose comparison with placebo. Biol Psychiatry 38:592602

Fawcett J (1997): The detection and consequences of anxiety in clinical depression. J Clin Psychiatry 58(Suppl 8):35-40

Feighner JP, Gardner EA, Johnston JA, Batey SR, Khayrallah MA, Ascher JA, Lineberry CG (1991): Double-blind comparison of bupropion and fluoxetine in depressed outpatients. J Clin Psychiatry 52:329-335

Filteau MJ, Baruch P, Lapierre YD, Bakish D, Blanchard A (1995): SSRIs in anxious-agitated depression: A post-hoc analysis of 279 patients. Int Clin Psychopharmacol $10: 51-54$
Goodman WK (1999): Obsessive-compulsive disorder: Diagnosis and treatment. J Clin Psychiatry 60(Suppl 18):27-32

Guy W (1976): ECDEU Assessment Manual for Psychopharmacology. Publication No. 76-338. Washington, DC, Superintendent of Documents, U.S. Government Printing Office, U.S. Department of Health, Education and Welfare

Hamilton M (1959): The assessment of anxiety states by rating. Br J Med Psychol 32:50-55

Hamilton M (1960): A rating scale for depression. J Neurol Neurosurg Psychiatry 23:56-62

Hamilton M (1967): Development of a rating scale for primary depressive illness. Br J Soc Clin Psychol 6:278-296

Henney JE (2000): Sertraline approved for posttraumatic stress disorder. JAMA 283:596

Joffe RT, Bagby M, Levitt A (1993): Anxious and nonanxious depression. Am J Psychiatry 150:1257-1258

Kavoussi RJ, Segraves RT, Hughes AR, Ascher JA, Johnston JA (1997): Double-blind comparison of bupropion sustained release and sertraline in depressed outpatients. J Clin Psychiatry 58:532-537

Pfizer, Inc. (1996): Sertraline $\left(\right.$ ZOLOFT $\left.^{\circledR}\right)$ Product Information. New York, Pfizer, Inc.

Quitkin FM, McGrath PJ, Stewart JW, Harrison W, Tricamo E, Wager SG, Ocepek-Welikson K, Nunes E, Rabkin JC, Klein DF (1990): Atypical depression, panic attacks, and response to imipramine and phenelzine. A replication. Arch Gen Psychiatry 47:935-941

Reimherr FW, Chouinard G, Cohn CK, Cole JO, Itil TM, LaPierre YD, Masco HL, Mendels J (1990): Antidepressant efficacy of sertraline: a double-blind, placebo- and amitriptyline-controlled, multicenter comparison study in outpatients with major depression. J Clin Psychiatry 51(Suppl 12B):18-27

Reimherr FW, Cunningham LA, Batey SR, Johnston JA, Ascher JA (1998): A multicenter evaluation of the efficacy and safety of 150 and $300 \mathrm{mg} / \mathrm{d}$ sustained-release bupropion tablets versus placebo in depressed outpatients. Clin Ther 20:505-516

Rush AJ, Batey SR, Donahue RMJ, Ascher JA, Carmody T, Metz A (2001): Does pretreatment anxiety predict response to either bupropion SR or sertraline? J Affect Disord 64:81-87

Rush AJ, Trivedi MH, Batey SR, Donahue RMJ, Carmody TJ, Houser TL, Ascher JA, Bolden-Watson C, Metz A (2000): Anxiolysis associated with antidepressant response to bupropion sustained release or sertraline. Int J Neuropsychopharmacol 3(Suppl 1):S235

Segraves RT, Kavoussi R, Hughes AR, Batey SR, Johnston JA, Donahue R, Ascher JA (2000): Evaluation of sexual functioning in depressed outpatients: A double-blind comparison of sustained-release bupropion and sertraline treatment. J Clin Psychopharmacol 20:122-128

Sheehan DV (1999): Current concepts in the treatment of panic disorder. J Clin Psychiatry 60(Suppl 18):16-21 
Simon GE, Heiligenstein JH, Grothaus L, Katon W, Revicki D (1998): Should anxiety and insomnia influence antidepressant selection: A randomized comparison of fluoxetine and imipramine. J Clin Psychiatry 59:49-55

Stokes P, Holtz A (1997): Fluoxetine tenth anniversary update: The progress continues. Clin Ther 19:1135-1250

Tollefson GD, Greist JH, Jefferson JW, Heiligenstein JH, Sayler ME, Tollefson SL, Koback K (1994): Is baseline agitation a relative contraindication for a selective serotonin reuptake inhibitor: A comparative trial of fluoxetine versus imipramine. J Clin Psychopharmacol 14:385-391

Tyrer PJ, Lee I, Edwards JG, Steinberg B, Elliott EJ, Nightingale JH (1980): Prognostic factors determining response to antidepressant drugs in psychiatric out-patients and general practice. J Affect Disord 2:149-156

Weihs KL, Settle EC, Batey SR, Houser TH, Donahue RMJ, Ascher JA (2000): Bupropion SR versus paroxetine for the treatment of depression in the elderly. J Clin Psychiatry 61:196-202 